\title{
Teacher's Perception of Continuous Assessment System at Basic Level
}

\author{
Chandra Badana Rai*
}

\begin{abstract}
The continuous assessment system (CAS) has been recognized as an integral part of everyday classroom instruction at the basic level of education. This study aims to explore the teachers' perceptions towards continuous assessment systems at the basic level. It was designed in a qualitative model and using a semi-structured interview schedule. For Participants, six basic level school teachers were selected purposely from three selected schools in Kathmandu district. The interviews covered sociodemographic data, perceptions towards CAS, teaching styles, and personal experience using CAS, and challenges towards using CAS. An inductive analysis was used to allow for the patterns and themes to emerge. The finding of the study showed that most of the teachers were positive and only a few had negative perceptions towards the CAS along with its tools like portfolio, project work, and homework. Lack of CAS training for teachers, insufficient materials, resources, and infrastructures also seems to be a great challenge to the teachers. This study revealed the necessity to conduct CAS training to the basic level teachers and provide sufficient materials for the effective use of CAS at the basic level.
\end{abstract}

Keywords: Teachers' perceptions, continuous assessment, education system, learning outcomes and CAS.

\section{Introduction}

The continuous assessment system (CAS) has been recognized as a vital part of everyday classroom instruction at the basic level of education in many developing countries, like Nepal. It is an important component of any teaching-learning process. Students need to be given assessment and follow-ups frequently to boost up the educational progress in the teaching and learning process. It is a key instrument to ensure quality education. "Continuous assessment is an ongoing process of gathering and interpreting information about student learning that is used in making decisions

${ }^{*}$ Ms. Rai is M.Phil scholar at Graduate School of Education in Tribuvan University, Kathmandu. She has been working as the head of Education Department at Koteshwor Multiple Campus, Kathmandu. 
about what to teach and how well students have learned"(Nitko, 2004,p.7).It refers to the use of several assessments during the academic period instead of a single final exam in the last weeks of the academic year. It is also referred to as frequent assessment (Rezaei, 2015). It can be used to improve students' learning activities as well as their engagement in the classroom (Holmes, 2015). In both activities, continuous assessment can be used to provide feedback to students and teachers. Furthermore, it can be used as a reward system for desired studying behavior (Admiral, Wubbels, and Pilot, 1999). Similarly, Arega (2014) has documented that there is significant evidence that continuous assessment is a powerful instrument for enhancing the attainment of learning outcomes to ensure quality education and academic excellence in education institutions. According to Gipps (2011), teachers have had to rely on continuous assessment to monitor their students' academic progress and performance. Iqbal (2017), states that continuous assessment can enhance student learning. Research suggests that the implementation of a continuous approach is not an easy task. Nsibande \&Modiba (2012) analyzed the factors challenging the implementation of continuous assessment in a large class size due to the shortage of funds to fulfill the necessary resources and lack of adequate train teachers. The above review shows that many educational systems all over the world have adopted this approach in evaluating learner's achievement in many subject areas.

A continuous assessment system was developed along with the liberal promotion system to reduce the failure rate, class repetition rate, and dropout rate of the learners. Department of Education, (2012) includes, "almost all the education plan of Nepal and national commission report has focused the need for regular assessment that is Continuous Assessment System(CAS)". In the same way, the 9th (1997-2002) and 10th (2002-2007) five-year plans started to introduce CAS for the primary level (National Planning Commission, 1997 \& National Planning Commission, 2002). The 10th fiveyear plan has particularly targeted to introduce CAS up to grade five based on the pilot experiments (NPC, 2002). According to the Curriculum Development Centre (2009), primary education curriculum 2062 (grade 1-3) and 2065 (4-7) have implemented the program of CAS in the evaluation system of government schools. At present, the students of grades 1-3 are upgraded based on the liberal promotion system with CAS. For grade 1-3 students, no pass marks are allocated in the evaluation system. It shows that CAS is a major criterion in the evaluation system of the primary level. Similarly, the students of classes $4-5$ are also evaluated by $50 \%$ based on CAS. Now, this trend is increased up to class eight at the basic level. In this way, the Continuous Assessment System is a major tool of assessment that is practiced regularly to reduce the failure rate, dropout rate and class repetition rate of the basic level learners, in the Nepalese context. 
Continuous assessment activities allow us to identify what our students are learning and enable them to improve the learning environment through our courses and academic programs. To ensure continuous learning and to enhance quality in education the continuous assessment system is the key to assist children individually for learning. Apart from that, it is also helpful to reduce dropouts on one hand and increase retention on the other. There is a policy provision to implement the Continuous Assessment System (CAS) in primary grades of Nepalese schools, which now has been extended to grade seven. One of the weaknesses found in the practices of CAS in Nepalese schools is the detachment of assessment from classroom teaching-learning; as a result, the use of assessment for formative purposes is minimal. In this regard (Poudel, et al., 2015), have stated that "assessment results have hardly been used in the teaching-learning process; rather it has been a ritual of filling the forms in many schools". The government of Nepal has now made the Continuous Assessment System mandatory in basic levels. However, many people are not clear about the proper implementation of CAS and factors that are affecting its implementation.

There are different views regarding the continuous assessment system and some of the teachers are also confused about this. The actual picture is not clear since there is very less information available on teachers' perceptions of the continuous assessment system in Nepal. Despite having lots of advantages, students are not willing to take part in the activities of the continuous assessment system which I believe is a serious problem in the field of teaching and learning. Hence, I want to explore how basic level teachers practice the activities of CAS in their classrooms. This study looked to investigate the teachers' perception towards continuous assessments and the effects of continuous systems on teaching and learning at the basic level. The outcome of the research may support the teachers in understanding the essence of the continuous assessment system and may help teachers in changing their attitude. Therefore, this study is aimed to explore the teachers' perceptions towards continuous assessment systems at basic level education.

\section{Materials and Methods}

I followed a qualitative research approach as I was exploring the experience of a basic level teacher. For this, I gathered information through open-ended questions to understand 'the world of human experience' (Cohen, Manion \& Morrison, 2007). It is particularly recommended for exploring experiences and perceptions from individuals' perspectives. The study was carried out during March 2019 AD in Kathmandu Metropolitan City of a Kathmandu district of Nepal. To explore teacher perceptions and challenges towards a continuous assessment system at the basic level, I purposely 
selected six participants coded as participant no. 1, 2,3,4,5, and 6. All Participants are teachers of a basic level from different three schools in Kathmandu district. Two teachers were chosen from each selected school as participants.

Data were collected from participants from the target population to explore teachers' perceptions and challenges towards CAS at the basic level. Semi-structured interviews were conducted with basic level teachers. The interviews covered socio-demographic data, perceptions towards CAS, teaching styles, and personal experience using CAS, and challenges towards using CAS. Participants were asked how they felt about CAS influencing their learning skills of the students and teaching styles; in particular how they might influence their ability to achieve and maintain quality education. They were also asked for their views on any other challenges to implementing a continuous assessment system at a basic level.

Interviews were tape-recorded and transcribed. The interviews lasted about one hour. Individual interviews were transcribed, coded, and analyzed. An inductive analysis was used because it allows the patterns, themes, and categories of analysis to emerge (Lincoln \& Guba, 1985). Two levels of qualitative analysis were conducted. The descriptive analysis described the respondents' life situations and characteristics. The thematic analysis elaborated the structures of basic constructs and new constructs that arose in the early analysis. Readers reviewed transcripts of the first interviews to identify all relevant ideas. Their notations were compared and discussed. The process was repeated for the second transcripts until there was agreement on the ideas and concepts. Some of the concepts were broken down into various sub-components of the theme. The next stage of analysis was to go back to the individual interviewee level to look at within-person consistency with each concept. The readers assembled and compared all the text references to a concept.

In this way, the readers ensured scientific rigor of the qualitative analysis by making sure the themes and contexts derived were correct in that credibility, reliability, and dependability can be demonstrated.

\section{Results and Discussion}

The study was completed after taking interviews with teachers' to understand their perceptions and challenges towards the CASS. All participants are teaching at a basic level and each had a face to face interview. I have analyzed the major challenges faced by the basic level teachers while using CAS in teaching and learning activities at basic level. To find out the teachers' challenges regarding CAS in class I had developed a teacher interview guideline. Based on this guideline, selected teachers had been interviewed about their perceptions and challenges of using CAS at the basic level. I 
have generated different themes regarding the teachers' perceptions and challenges of CAS based on their interviews, which are analyzed below.

\section{Teachers' Perceptions of Continuous Assessment System}

Most of the participated teachers are positive toward the use of CAS in teaching and learning. CAS with its other tools like homework, classwork, self-correction, and project work assess the students' progress and help the teachers as well as students to take correct action. In this sense, participant-1 reported:

I always check the students' homework and classwork regularly and find out students' mistakes. From this, students can get real information about their performance in learning activities.

Here, participant-1 has his own opinion of using homework and classwork to assess every progress regarding learning activities. According to his belief, he uses homework and classwork to find out the real mistakes regarding reading and writing. From this CAS system, the students themselves and the teacher can get actual performance. Likewise, participant-3 has different insight or CAS. He has reported:

CAS has broken the paper-pencil test of the evaluation system in Nepal. It has brought different assessment tools like portfolio, observation, self-correction, and project work which help to present learners' actual performance in learning activities every time.

Above perceptions are very important that at present, the old paper-pencil test is substituted by the CAS and its other components like project work, observation, and portfolio which help the teacher to assess every progress of students in learning. Furthermore, Students can get clear information about their tasks. Similarly, participant4 focuses on developing the portfolio as a modern tool of the CAS to develop the learning abilities of students. She said:

Classwork, homework, and observation can play important roles to improve the learners' performance. From these tools, the students can develop their self-study habits which are directly linked to the development of learning skills. A portfolio is also seen as an effective tool to develop learning ability by collecting good pieces of writing and creative work to keep a record of progress every time. Here, she added a different perception regarding CAS than previous participants. The use of tools of CAS like observation, portfolio, and project work in the class, makes the students more innovative, creative, and self-dependent for learning. Moreover, as a new tool of CAS, a portfolio helps the learners to collect information.

All the perceptions, under this theme, conclude that CAS and its tools like homework, classwork, project work, self-correction, classroom participation, and portfolio 
maintenance help the teacher to assess the students' progress about learning skills developed every time. From this, students can get the true pictures of their progress and modify their learning strategies with proper improvements. So, CAS helps to understand the real condition of teaching and learning activities for both teachers and learners respectively.

Some participating teachers' have a negative perception of the continuous assessment system. They simply do not like teaching classes with a continuous assessment system. Through qualitative analysis, the teachers suggested that a continuous assessment system increases their workload and is very time-consuming. Furthermore, students have a very poor attitude towards studies because of the continuous assessment system. Some students take advantage of the continuous assessment system since they know that everyone will be passing so they do not do much work. Participant-2 suggested-

Continuous assessment system does not help students' in learning. The continuous assessment gives rise to duplication, when students are absent, they tend to copy the task from others and sometimes the parents or elders do the task for the students.

Two participants among the six share that the task of portfolio maintenance is ineffective due to the teachers' limited time and resources. In this regard, participant-5 says:

Maintaining students' portfolios is itself very challenging for the teacher.

Furthermore, collecting students' information regarding learning skills, the teachers have to manage each portfolio for an individual within a limited time.

Here, the teacher has a different perception towards the management of learner individual portfolios. It is very difficult because of the limited time provided to the teacher. He has realized that the time of 45 minutes is not suitable to record all information of the students in the classroom. So, managing a portfolio of students at a basic level is difficult and not practicable for them.

\section{Materials, Resources, and Infrastructures for Continuous Assessment System}

This theme is developed based on interviews with the majority of the interviewee. Regarding challenges of CAS in teaching and learning, the teachers expressed that there is a lack of appropriate materials, resources, and infrastructures for the effective practice of CAS in teaching, more particularly in teaching and learning activities at the basic level.

CAS is the combined form of various means and materials. It requires many resources or materials of CAS like papers, files, and separate racks for portfolio, 
individual recording system, and progress charts. As the interviewee shared, CAS practice in Nepalese schools found a very poor situation; they even don't have access to fundamental CAS materials like forms and files. With further supporting points, participant-1 shared

There are many challenges to make the means and materials of CAS in our school. Sometimes when we ask for paper and record files and other essential materials to maintain the portfolio of the students, the school administration does not provide that materials in time and those are difficult to manage ourselves.

In these interviews, the interviewee reported that there is a lack of basic record files to file the students writing for further use which is a very basic material for CAS. This evidence proved that there is a lack of basic materials for CAS in government schools. Most of the basic level teachers in the government schools are facing the same problems or challenges of materials while practicing CAS in the teaching field. Not only materials and resources, but the practices of CAS also require other infrastructures like racks, extra rooms, and classroom management. This theme is generated from the interviews of participant 3 who reported:

Poor infrastructure is a problem for the teacher. In our school, there are no proper racks to manage the students' portfolios, which are the main challenge to implement CAS.

As the participant reported, most of the government schools of Nepal do not have proper physical infrastructures to manage the CAS and its tools like portfolios. According to the above-mentioned interviews, even the school has not provided simple racks to keep the individual portfolio of student tasks. So most of the schools in Nepal are unable to manage sufficient physical infrastructures required in the practice of CAS, which is a burning challenge for the teachers. Participant 4 reported a similar challenge:

Poor infrastructures are being a challenge to implement CAS. In my school, there are not sufficient rooms, desks and benches, and we cannot imagine adding other extra rooms and racks for the CAS. It is not possible for us to afford it.

From the above views, it is analyzed that most of the basic level teachers are facing the challenge of poor infrastructures for the proper use and implementation of CAS. In case of the limited rooms and buildings, we cannot imagine building infrastructures like separate rooms, tables, and racks which are the main challenge for the teachers to use CAS successfully at a basic level in Nepal. In this way, from these all interviews it is found that insufficient resources and materials and poor infrastructures are the great challenges for the basic level teachers to use CAS in the teaching and learning process. As a result of poor infrastructures, teachers of basic levels are not able to apply CAS in their classes properly. 


\section{Workload and Time for Continuous Assessment System}

This theme is also a challenge for teachers to implement CAS in classes, based on interviews reported by participant 2 and 3. In the context of Nepal, most of the teachers are engaged in a lot of tasks such as teaching, homework checking, discussing, and involving the students in project work in the bound and limited time of 45 minutes. Because of that, they could not use CAS in their classroom teaching, which is being a major challenge for the teachers. Participant 2 reports her challenge:

I felt that the heavy workload of the teacher is also a problem for the teacher.

$\mathrm{He} / \mathrm{she}$ has to teach, take attendance, use materials, discuss with students, check homework and classwork, and assess their performance within the limited time of 45 minutes.

The participant has expressed her view about the heavy workload and limited time bound for the teachers as a challenge of CAS in teaching and learning activities at the basic level. As she reported most of the teachers in Nepal are very busy with teaching tasks only. They have to teach $6 / 7$ classes per day, so they cannot practice CAS in their class. The teacher is provided 45 minutes for a period which is not fully sufficient to use the CAS and its tools like project work. So, heavy workload and limited time-bound for teachers are major challenges to use CAS at a basic level in Nepal.

\section{Training Programs of Continuous Assessment System for the Teachers}

This theme is developed based on the interviews interviewed by the two respondents, respondents 1 and 4 regarding the challenges of CAS in teaching and learning skills at the basic level. This theme is a challenge of using CAS, most of the basic level teachers are either untrained or unaware or unskilled about using CAS. The training agencies are only providing training about the teaching methodology and content but not about how to assess the students' performance through the CAS. Regarding this, participant-1shares:

There is no training for the teachers regarding ways of using CAS. Without proper ideas of using CAS, the teachers cannot use CAS and its tools like a portfolio. As I have experienced, training agencies have not provided any training programs for the teachers about the use of CAS. So, from my experiences, the lack of proper training for the basic level teachers about CAS is a challenge behind its effective implication. 
These above views, tell that without proper training to implement the CAS, the teachers cannot use the CAS and its other tools effectively. In Nepal, the training agencies are not providing efficient training to the basic level teachers about the ways of practicing CAS, how we make an effective CAS practice of CAS, and what are the new methods of using CAS. Most of the teachers are using CAS based on their styles. As reported by respondent 1 , most of the basic level teachers have not experienced the training for using CAS. Some tools like portfolio maintenance are very difficult to use in the classroom without proper ideas and skills which most of the basic level teachers lack. Due to the lack of teachers who are well trained about the CAS, it is not fully implemented in all government schools of Nepal. Similarly, participant-6, reports:

I have participated in the training, conducted by different agencies but I do not have any experience of participating in CAS training. CAS is a new concept for the teachers so they cannot use CAS effectively without proper training. I have seen the lack of training programs for the teachers about CAS as a problem or challenge in teaching and learning activities.

The above views also show the lack of training for the teacher about the practice of CAS is a great challenge in the field of assessment as well as teaching and learning in class. There are not any specific training programs for the basic level teachers about CAS. The use of CAS in the teaching field is significant for self-initiated learning that is why most government schools are using it according to their own ways... So, the lack of CAS training to the teachers is regarded as a great challenge for the teachers to use CAS effectively and significantly.

\section{Conclusion}

Teachers are the fundamental agents for the implementation of CAS at basic level schools. So, this study has tried to explore teachers' perceptions of CAS. The results of the interview showed that many teachers have agreed that CAS needs to be implemented in the classes for an efficient teaching and learning process whereas some have disagreed with it. It can be concluded that challenges like a lack of proper resources and materials like papers, files, racks, and other materials are not allowing CAS to be fully implemented at basic level classes. Most of the teachers have expressed that a continuous assessment system is helping students in the learning process and reducing the pressure of examination to the students at the basic level. 


\section{References}

Admiral, W., Wubbels, T., \& Pilot, A. (1999). College teaching in legal education:

Teaching method, students' time-on-task, and achievement. Research in higher education, Vol. 40(6), pp. 687-704.

Arega, M. (2014). Classroom assessment manual for primary and secondary school teachers. National Educational Assessment and Examination Agency. Addis Ababa, University, Ethiopia

Curriculum Development Centre, (2009).Continuous students' evaluation resource materials. Bhaktapur: CDC.

Department of Education, (2012). Continuous student evaluation program instruction. Kathmandu: Ministry of Education Department of Education.

Gipps, C. (2011). Beyond Testing (Classic Edition): Towards a theory of educational assessment. Milton Park, Abingdon, London: Routledge Publication.

Holmes, N. (2015). Student perceptions of their learning and engagement in response to the use of continuous e-assessment in an undergraduate module. Assessment and evaluation in higher education, Vol. 40(1), pp. 1-14.

Iqbal, M. (2017). Effect of Continuous Assessment Techniques on Students'

Performance at Elementary Level. Bulletin of education and research, Vol. 239 (1), pp. 91-100.

Lincoln, Y. Guba, E. (1985). Naturalistic Inquiry.Beverly Hills, CA: Sage Publication.

National Planning Commission, (1997). The Ninth National Plan (1997-2002).

Kathmandu: National Planning Commission.

NPC, (2002). The Tenth National Plan (2002-2007). Kathmandu: National Planning Commission.

Nitko, E. G. (2004). Educational Assessment of Students. Ohio: Merrill Prentice Hall.

Nsibande, R. N., \& Modiba, M. M. (2012). 'I just do as expect': Teachers' implementation of continuous assessment and challenges to curriculum literacy. Research Papers in Education, Vol. 27(5), pp. 629-645.

Poudel, L. N. et al. (2015). School sector development plan on student assessment and examinations (unpublished a background paper prepared for developing SSDP). SSDP Thematic Working Group, MOE/ GON.

Rezaei, A. R. (2015). Frequent collaborative quiz taking and conceptual learning. Active learning in higher education, Vol. 16(3), pp. 187-196. 